Check for updates

Cite this: RSC Adv., 2017, 7, 43567

\title{
Fast screening of whole blood samples for early detection and monitoring of thyroid diseases
}

\author{
Raluca-loana Stefan-van Staden (D) *ab and Grigorina Mitrofan ${ }^{a}$ \\ This paper described a fast and reliable method for the screening of whole blood for TSH, L-T $4, L-T_{3}$ and \\ $\mathrm{D}-\mathrm{T}_{4}$ using stochastic sensors. The main advantage of this method is the possibility of tracing the precise \\ diagnosis of thyroid dysfunction from a single whole blood sample by multianalyte screening in one run, \\ with low cost. Six stochastic microsensors based on mixtures between inulins: Frutafruit TEX (TEX) and \\ inulin Inutec (IN), and ionic liquids: L-phenylalanine-tert-butyl-ester-lactate (L-PheC ${ }_{4}$-Lac), L-alanine- \\ tert-butyl-ester-L-lactate $\left(\mathrm{L}-\mathrm{AlaC}_{4}\right.$-LaC) and L-alanine-tert-butyl-ester-nitrate ( $\left.\mathrm{L}-\mathrm{AlaC}_{4}-\mathrm{NO}_{3}\right)$, physically \\ immobilized in a diamond paste matrix were designed and used for the screening tests. The tests were \\ reliable for the assay of $\mathrm{TSH}, \mathrm{L}-\mathrm{T}_{4}, \mathrm{~L}-\mathrm{T}_{3}$ and $\mathrm{D}-\mathrm{T}_{4}$ in whole blood samples, with recoveries higher than \\ $98.00 \%$ with RSD values lower than $1.00 \%$ being recorded.
}

Received 7th August 2017

Accepted 5th September 2017

DOI: 10.1039/c7ra08724a

rsc.li/rsc-advances

or inulins for the detection of thyroid hormones has been demonstrated elsewhere., ${ }^{3,4}$

One of the most frequent endocrine diseases are those of thyroid. ${ }^{5}$ The key assays that are used to detect thyroid dysfunction are serum thyroid stimulating hormone (TSH) and the main circulating thyroid hormones thyroxine ( $\left.\mathrm{f}-\mathrm{L}-\mathrm{T}_{4}\right)$ and triiodothyronine (f-L-T $\left.\mathrm{T}_{3}\right){ }^{1}$ The level of TSH is used by physicians as a screening test for thyroid diseases. Elevated concentrations of TSH usually represents a sign of a decreased $\mathrm{L}^{-\mathrm{T}_{4}}$ or $\mathrm{L}-\mathrm{T}_{3}$ production, while suppressed levels can point an excessive activity of thyroid gland. ${ }^{1}$ The determination of TSH serves not only as a preliminary test for thyroid status, but the high level of TSH is associated with increased thyroid cancer incidence and advanced-stage disease. ${ }^{6}$

For $\mathrm{L}^{-\mathrm{T}_{4}}$ and $\mathrm{L}-\mathrm{T}_{3}$ equilibrium dialysis and ultrafiltration represented the gold-standard methods $\mathrm{s}^{7,8}$ but they are no longer used, being expensive and time consuming. Other methods such as MS ${ }^{9}$ LC-MS $^{10}{ }^{10}$ HPLC, ${ }^{11}$ RIA $^{12}$ and CLEIA ${ }^{13}$ have been developed. Also for the assessment of TSH the most used methods were developed based on immunoassay techniques such as ECLIA, ${ }^{14,15}$ ELISA, ${ }^{16}$ IRMA, ${ }^{17}$ EIA $^{18}$ and RIA. ${ }^{19}$ Improved or newer technologies are proving to be viable alternatives, sometimes offering better sensitivity, increased throughput and lower matrix interference. Thus, $\mathrm{L}-\mathrm{T}_{3}, \mathrm{~L}-\mathrm{T}_{4}$ and $\mathrm{D}-\mathrm{T}_{4}$ have been analyzed with different electrochemical sensors, ${ }^{20-22}$ biosensors $^{23}$ and immunosensors. ${ }^{24}$ For the assay of TSH, immunosensors, ${ }^{25}$ biosensors ${ }^{26}$ and optical sensors ${ }^{27}$ have been reported. Recently, reliable methods of analysis were proposed for assay of biomarkers specific to different illnesses..$^{28-30}$

This paper proposed a fast and reliable method for the ${ }^{a}$ Faculty of Applied Chemistry and Materials Science, Politehnica University of Bucharest, 1-7 Polizu St., Bucharest, 011061, Romania. E-mail: ralucavanstaden@ gmail.com; Tel: +40751507779

${ }^{b}$ Laboratory of Electrochemistry and PATLAB Bucharest, National Institute of Research for Electrochemistry and Condensed Matter, 202 Splaiul Independentei St., Bucharest, 060021, Romania

screening of whole blood for $\mathrm{TSH}_{2} \mathrm{~L}-\mathrm{T}_{4}, \mathrm{~L}^{-} \mathrm{T}_{3}$ and $\mathrm{D}-\mathrm{T}_{4}$ using possibility of tracing the precise diagnosis of thyroid 
dysfunction from a single whole blood sample by multianalyte assay in one run, with low cost. Six stochastic microsensors based on mixtures between inulins: Frutafruit TEX (TEX) and inulin Inutec (IN), and ionic liquids: L-phenylalanine-tert-butylester-lactate ( $\mathrm{L}_{-}-\mathrm{PheC}_{4}$-Lac), L-alanine-tert-butyl-ester-L-lactate (L-AlaC 4 -Lac) and L-alanine-tert-butyl-ester-nitrate $\left(\mathrm{L}-\mathrm{AlaC}_{4}-\mathrm{NO}_{3}\right)$ physically immobilized in a diamond paste matrix were designed and used for the screening tests.

\section{Experimental}

\section{Materials and methods}

Reagents and materials. The standard solutions of free $\mathrm{L}-\mathrm{T}_{3}$ (f-L- $\left.\mathrm{T}_{3}\right), \mathrm{L}_{-} \mathrm{T}_{4}\left(\mathrm{f}-\mathrm{L}-\mathrm{T}_{4}\right), \mathrm{D}-\mathrm{T}_{4}\left(\mathrm{f}-\mathrm{D}-\mathrm{T}_{4}\right)$ and $\mathrm{TSH}$ were prepared in phosphate buffer solution $(\mathrm{pH}=7.50)$. The $\mathrm{pH}$ was adjusted using small amounts of $0.1 \mathrm{~mol} \mathrm{~L}^{-1} \mathrm{NaOH}$ or $\mathrm{HCl}$ solution. Deionised water obtained from a Millipore Direct-Q 3 System

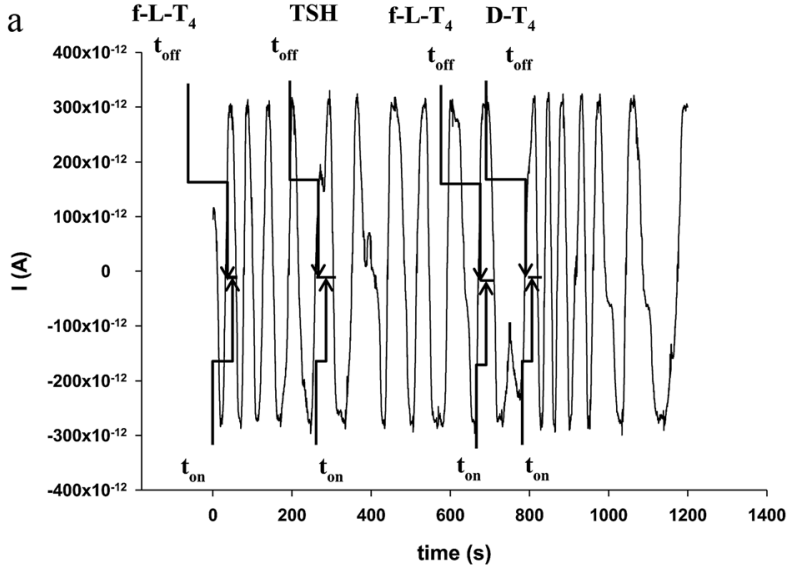

C

f-L-
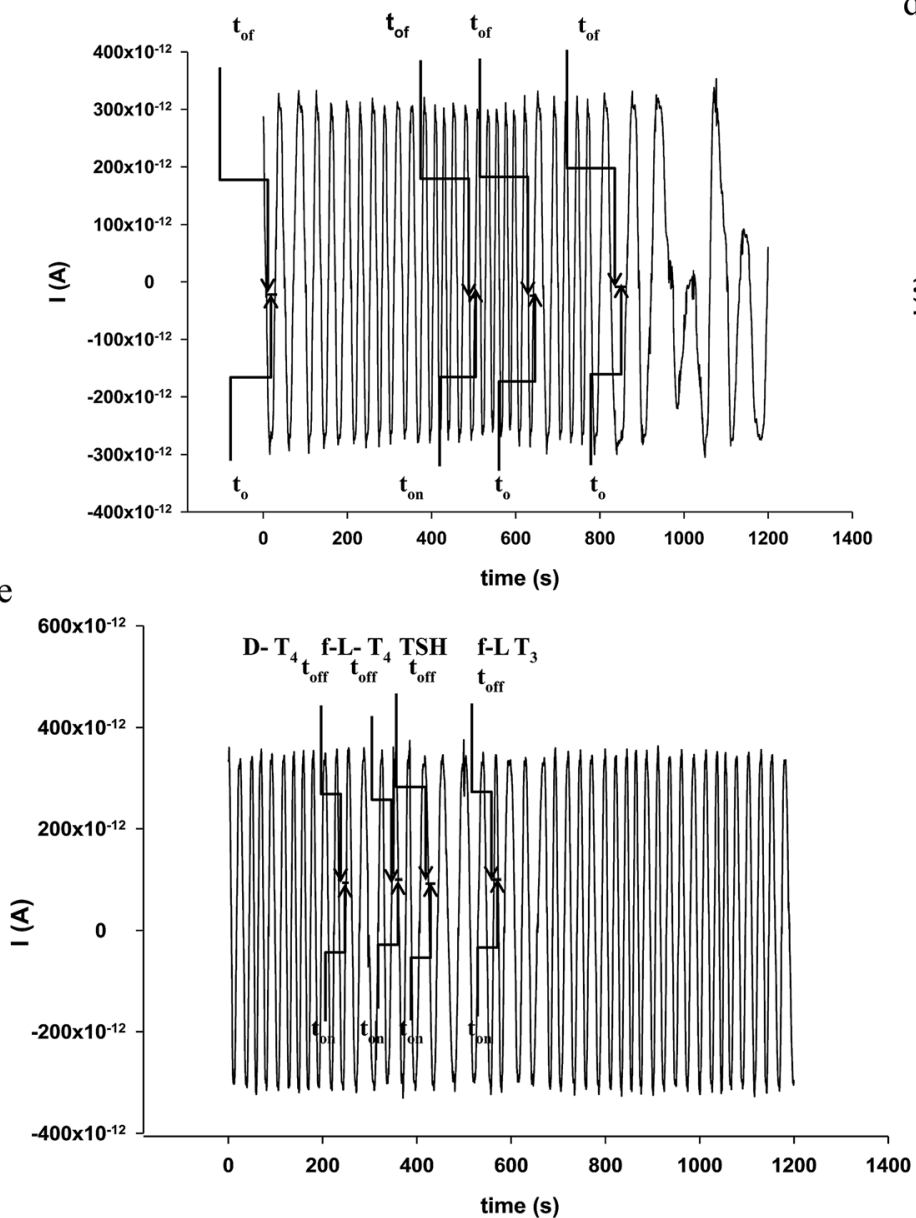

b

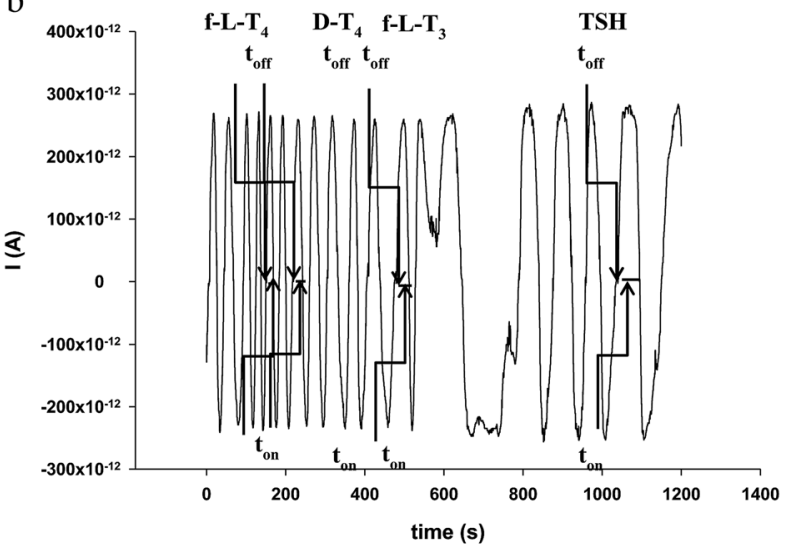

d

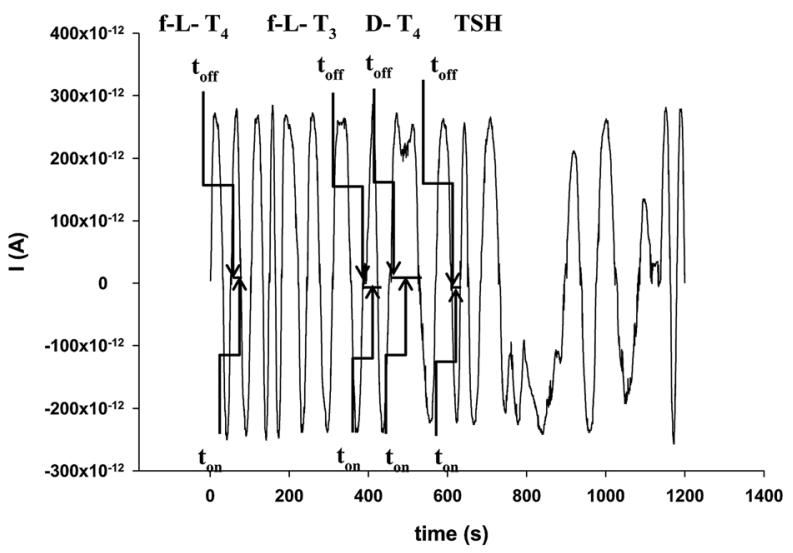

f

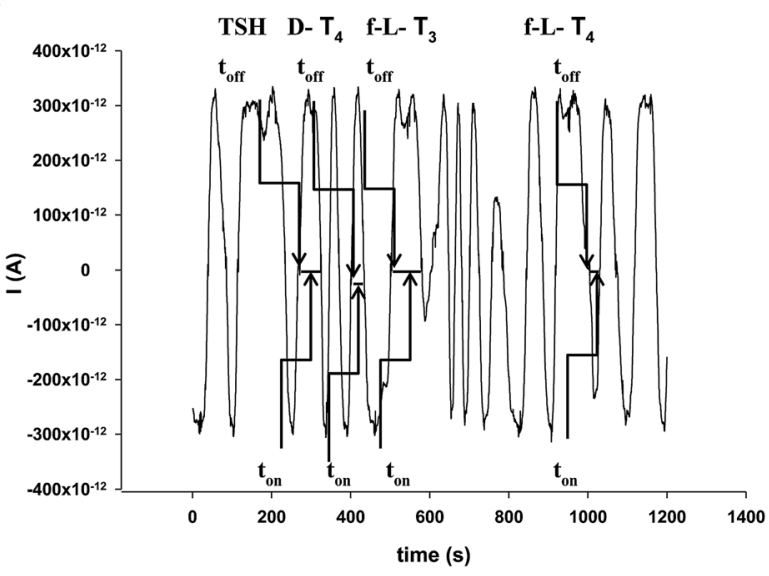

Fig. 1 Screening the whole blood for $\mathrm{f}-\mathrm{L}-\mathrm{T}_{3}, \mathrm{f}-\mathrm{L}-\mathrm{T}_{4}, \mathrm{f}-\mathrm{D}-\mathrm{T}_{4}$ and $\mathrm{TSH}$ using the microsensor based on: (a) IN-L-Ala- $\mathrm{C}_{4}-\mathrm{NO} \mathrm{O}_{3}$; (b) IN-L-Ala-L-Lac; (c) IN-L-Phe-C ${ }_{4}-\mathrm{L}-\mathrm{Lac}$; (d) TEX-L-Ala-C ${ }_{4}-\mathrm{NO}_{3}$; (e) TEX-L-Ala-L-Lac; (f) TEX-L-Phe-C 4 -L-LAC. 
(Molsheim, France) was used for all solutions preparation. Natural diamond powder with particle size of $1 \mu \mathrm{m}(99.9 \%)$, free $\mathrm{L}^{-} \mathrm{T}_{3}$ (f-L- $\left.\mathrm{T}_{3}\right), \mathrm{L}^{-} \mathrm{T}_{4}\left(\mathrm{f}-\mathrm{L}-\mathrm{T}_{4}\right), \mathrm{D}-\mathrm{T}_{4}\left(\mathrm{f}-\mathrm{D}-\mathrm{T}_{4}\right), \mathrm{TSH}$, monosodium, disodium phosphate and ionic liquids $\mathrm{L}$-phenylalanine-tertbutyl-ester-lactate $\quad\left(\mathrm{L}-\mathrm{PheC}_{4}\right.$-Lac), L-alanine-tert-butyl-ester-Llactate $\left(\mathrm{L}_{-}-\mathrm{AlaC}_{4}\right.$-Lac $)$ and $\mathrm{L}$-alanine-tert-butyl-ester-nitrate $\left(\mathrm{L}-\mathrm{AlaC}_{4}-\mathrm{NO}_{3}\right.$ ) were purchased from Sigma Aldrich (Milwaukee, USA). Inulin Frutafruit TEX (TEX) was provided by Sensus (Roosendaal, Netherlands) and inulin Inutec (IN) was provided by Orafti Non Food (Oreye, Belgium). Paraffin oil was purchased from Fluka (Buchs, Switzerland).

Standard solutions of different concentration were obtained by serial dilution. All solutions were fresh prepared before measurements. When not in use, all the solutions were stored in the freezer at $2-8{ }^{\circ} \mathrm{C}$.

Apparatus. PGSTAT 302 was used for the recording of all the chronoamperometric measurements using a software Ecochemie version 4.9. The conventional electrochemical cell was constituted by the working electrode, $\mathrm{Ag} / \mathrm{AgCl}\left(0.1 \mathrm{~mol} \mathrm{~L}^{-1} \mathrm{KCl}\right)$ as reference electrode and Pt as counter electrode.

Microsensors design. The matrix selected was modified diamond paste (DP). Ionic liquids such as L-phenylalanine tertbutyl ester lactate $\left(\mathrm{L}\right.$-PheC $\mathrm{C}_{4}$-Lac), L-alanine tert-butyl ester L-lactate ( $\left.\mathrm{L}^{-}-\mathrm{AlaC}_{4}-\mathrm{Lac}\right)$, L-alanine tert-butyl ester nitrate ( $\mathrm{L}^{-} \mathrm{AlaC}_{4}$ $\mathrm{NO}_{3}$ ) and inulins TEX and IN were selected as modifiers. For the preparation of diamond paste we used natural monocrystalline diamond powder mixed with paraffin oil; $12 \mu \mathrm{L}$ of each ionic liquid solution $\left(10^{-3} \mathrm{~mol} \mathrm{~L}^{-1}\right)$ and $12 \mu \mathrm{L}$ of each inulin solution $\left(10^{-3} \mathrm{~mol} \mathrm{~L}^{-1}\right)$ were added to $100 \mathrm{mg}$ diamond paste to give six modified pastes.

Each modified paste was places in a plastic tube with an internal diameter of the active surface of $300 \mu \mathrm{m}$. The electric contact was obtained using an Ag wire inserted into the modified paste. The surface of the microsensor was renewed by polishing with aluminum paper and wetted with deionised water before using. When not in use, the microelectrodes were stored in a dry state at room temperature.

Recommended procedures: stochastic method. All the stochastic measurements were performed using chronoamperometry at a constant potential of $125 \mathrm{mV}$. The electrochemical cell was filled with blood samples without any pretreatment. The $t_{\text {off }}$ values (signatures of thyroid hormones) were identified for TSH, f-L- $\mathrm{T}_{4}, \mathrm{f}-\mathrm{L}-\mathrm{T}_{3}$ and $\mathrm{f}-\mathrm{D}-\mathrm{T}_{4}$ (Fig. 1). The values of $t_{\text {on }}$ were determined and the unknown concentrations of TSH, f-L-T $\mathrm{T}_{3}, \mathrm{f}-\mathrm{L}-\mathrm{T}_{4}$ and $\mathrm{f}-\mathrm{D}-\mathrm{T}_{4}$ were obtained by inserting the value $1 / t_{\text {on }}$ in the related equation of calibration $\left(1 / t_{\text {on }}=\right.$ f (conc)).

\section{Sample preparation}

Whole blood samples. Whole blood samples were obtained from 9 patients, who have been previously evaluated in the Elias Emergency University Hospital Bucharest. All experiments were performed in compliance with the EU guidelines, and approved by the medical ethics committee at University of Medicine and Pharmacy "Carol Davila", Bucharest, Romania (Ethics committee approval no. 11/2013). Informed consents were obtained from human participants of this study. The apparatus cell was filled with the whole blood samples and the stochastic measurements were performed. The unknown concentrations were determined from the calibration graphs as described above in the Recommended procedure section.

\section{Results and discussions}

\section{Response characteristics of the stochastic sensors}

The response of stochastic sensors is based on channel conductivity, when a fixed potential is applied. Accordingly, for the assay of the thyroid hormones a potential of $125 \mathrm{mV} v s$. $\mathrm{Ag} / \mathrm{AgCl}$ was applied. The measurement process of a single molecule is taking place in two stages: the first stage on which the molecule is entering the channel, blocking it - when the current is dropping to zero value (the time designed as $t_{\mathrm{off}}$, that the molecule needs to go into the channel is called signature of the analyte and depends on the size and geometry of the molecule, its capacity of unfolding and of velocity needed to enter the channel); the second stage is the one on which binding with the wall of the channel are taking place (the time spend for these processes is called $t_{\mathrm{on}}$ - which is measured between two $t_{\text {off }}$ events): ${ }^{3,4}$

$$
\begin{aligned}
\mathrm{Ch}_{(\mathrm{i})}+\mathrm{f}-\mathrm{L}-\mathrm{T}_{3(\mathrm{i})} & \Leftrightarrow \mathrm{Ch} \cdot \mathrm{f}-\mathrm{L}^{-\mathrm{T}_{3(i)}} \\
\mathrm{Ch}_{(\mathrm{i})}+\mathrm{f}-\mathrm{L}-\mathrm{T}_{4(\mathrm{i})} & \Leftrightarrow \mathrm{Ch} \cdot \mathrm{f}-\mathrm{L}-\mathrm{T}_{4(\mathrm{i})} \\
\mathrm{Ch}_{(\mathrm{i})}+\mathrm{f}-\mathrm{D}-\mathrm{T}_{4(\mathrm{i})} & \Leftrightarrow \mathrm{Ch} \cdot \mathrm{f}-\mathrm{D}-\mathrm{T}_{4(\mathrm{i})} \\
\mathrm{Ch}_{(\mathrm{i})}+\mathrm{TSH}_{(\mathrm{i})} & \Leftrightarrow \mathrm{Ch} \cdot \mathrm{TSH}_{(\mathrm{i})}
\end{aligned}
$$

where $\mathrm{Ch}$ is the channel, and $\mathrm{i}$ is the interface, followed by redox processes. In the case of simultaneous investigation of multianalytes, each of them entering the channel in an order given by their size, geometry, stereochemistry, capacity of unfolding and velocity of passing through the opening of the channel; therefor for each of them their signature ( $t_{\text {off }}$ value, Fig. 1) followed a peak are seen in the diagram obtained after screening of whole blood..$^{31-33}$

Response characteristics are shown in Table 1. Different signatures of $\mathrm{TSH}, \mathrm{f}-\mathrm{L}-\mathrm{T}_{4}, \mathrm{f}-\mathrm{L}-\mathrm{T}_{3}$ and $\mathrm{f}-\mathrm{D}-\mathrm{T}_{4}$ were obtained for the proposed sensors; there are only two sensors for which the differences between the signatures of TSH, f-L- $\mathrm{T}_{4}$, f-L- $\mathrm{T}_{3}$ and f-D$\mathrm{T}_{4}$ are very small: the sensors based on IN-L-Ala-NO $\mathrm{N}_{3}$, and TEX-LPhe- $\mathrm{C}_{4}$-L-Lac and therefore difficult to assess in real samples. All sensors exhibited high sensitivity for the simultaneous assay of $\mathrm{TSH}, \mathrm{f}-\mathrm{L}-\mathrm{T}_{4}, \mathrm{f}-\mathrm{L}-\mathrm{T}_{3}$ and $\mathrm{f}-\mathrm{D}-\mathrm{T}_{4}$. The lowest limit of determination for $\mathrm{f}-\mathrm{L}-\mathrm{T}_{3}$ was achieved using the sensor based on IN-L-Ala-C $\mathrm{C}_{4} \mathrm{~L}^{-}$ Lac, while for $\mathrm{f}-\mathrm{L}_{-} \mathrm{T}_{4}$ was achieved using the sensor based on IN-LPhe- $\mathrm{C}_{4}$-L-Lac, and for $\mathrm{f}-\mathrm{D}-\mathrm{T}_{4}$ the lowest limit of determination was given by the sensor based on TEX-L-Ala- $\mathrm{C}_{4}-\mathrm{L}-\mathrm{Lac}$. For TSH assay, no differences in limit of determination were recorded when the six sensors' response characteristics were determined. Regarding all response characteristics as well as the signatures of the hormones, the sensor of choice for simultaneous assay of thyroid hormones is the one based on TEX-L-Ala- $\mathrm{C}_{4}-\mathrm{NO}_{3}$-L-Lac.

The sensors were used for more than 3 months when their sensitivities' RSD (\%) values did not exceed $1.00 \%$, proving 


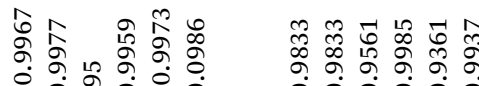

\|

$1=0$
$0=0$

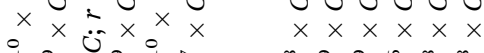

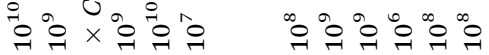

$\times \times \circ \times \times x$

$\times \times \times \times \times \times$

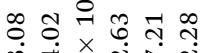

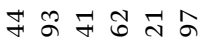

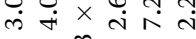

的的的 的

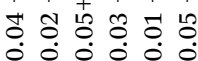

$++++++$

ڤ.

|| || || || ||

|| || || || || ||

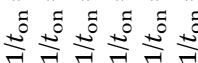

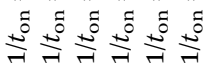

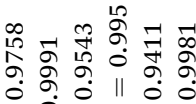

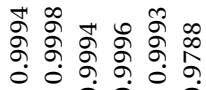

||

U்

||

ن்

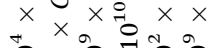

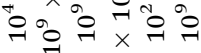

$\times-1 \times \infty \times x$

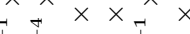

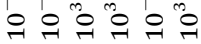

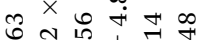

त ते लें के

$\times \times \times \times \times \times$

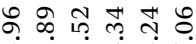

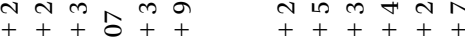

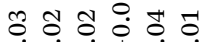

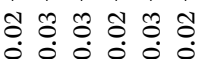

|| || || || || || || || || || ||

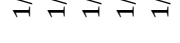

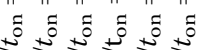

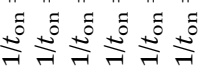

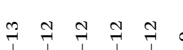

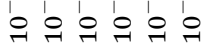

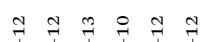

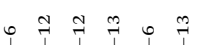

윽으응ㅇㅇㅇㅇㅡ

웅응ㅇㅇㅇㅇㅇㅇㅇ

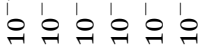

$\times \times \times \times \times$

$\begin{array}{llllll} & \times & \times & \times & \times & \times \\ - & 4 & + & - & \infty\end{array}$

$\times \times \times \times \times \times$

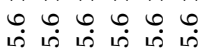

$\therefore$ 웅을

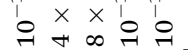

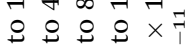

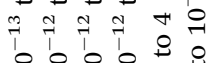

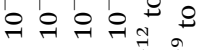

$\begin{array}{lllll}x & \times & \times & \times & 1 \\ +\infty & n & 0\end{array}$

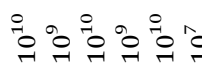
$\times \times \times \times \times \times$

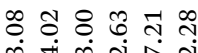

윽 욱 욱 웅 웅

$\times \times \times \times \times x$

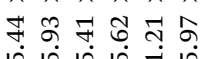

윽웅응

$\times \vec{x} \times \vec{x} \times x$

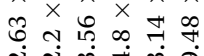

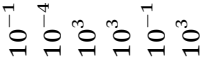
$x \times x \times x \times$

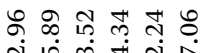

\section{$H-H$ 今气 今。}

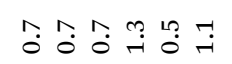

$\vec{i}-7+40,0$

ت্்

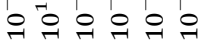

$\times \times \times \times \times \times$

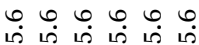

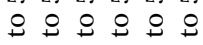

욱우웅우욱

$\times \times \times \times \times \times$

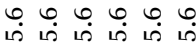

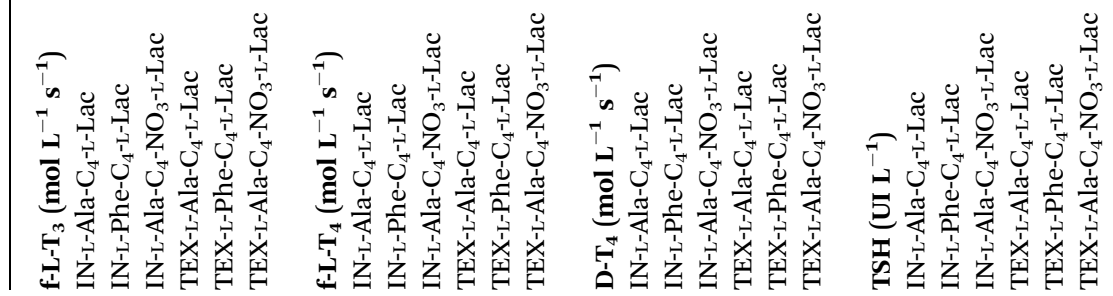


that the sensors are stable for this period, when accurate and precise determinations were performed for whole blood samples.

The selectivity of sensors is given for this type of sensors by the signatures recorded for each compound analysed with the same sensor. The sensors were tested for $\mathrm{f}-\mathrm{L}-\mathrm{T}_{3}, \mathrm{f}-\mathrm{L}-\mathrm{T}_{4}, \mathrm{f}-\mathrm{D}-\mathrm{T}_{4}$,
TSH and thyroid hormone receptor; different values were obtained for each of the compounds when the same sensor was used. The different values obtained for the signatures made possible the correct identification of the signal of the hormones in the diagrams (Fig. 1), and accordingly reliable qualitative analysis followed by quantitative analysis.

Table 2 Determination of $f-L-T_{4}, f-D-T_{4}, f-L-T_{3}$ and TSH in whole blood samples using the stochastic microsensors

\begin{tabular}{|c|c|c|c|c|c|}
\hline Sample no. & Microsensor based on & $\mathrm{f}-\mathrm{L}-\mathrm{T}_{3}\left(\mathrm{ng} \mathrm{dL}^{-1}\right)$ & $\mathrm{f}-\mathrm{L}-\mathrm{T}_{4}\left(\mathrm{ng} \mathrm{dL}^{-1}\right)$ & f-D-T ${ }_{4}\left(n g \mathrm{dL}^{-1}\right)$ & 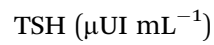 \\
\hline \multirow[t]{5}{*}{1} & IN-L-Ala-C 4 -L-Lac & $53.99 \pm 0.21$ & $6.99 \pm 0.01$ & $0.16 \pm 0.01$ & $0.056 \pm 0.003$ \\
\hline & IN-L-Phe-C 4 -L-Lac & $54.05 \pm 0.20$ & $6.00 \pm 0.05$ & $0.14 \pm 0.01$ & $0.061 \pm 0.002$ \\
\hline & TEX-L-Ala-C 4 -L-Lac & $53.93 \pm 0.20$ & $7.08 \pm 0.03$ & $0.17 \pm 0.02$ & $0.067 \pm 0.003$ \\
\hline & TEX-L-Phe-C ${ }_{4}$-L-Lac & $54.28 \pm 0.18$ & $6.06 \pm 0.02$ & $0.13 \pm 0.03$ & $0.049 \pm 0.002$ \\
\hline & TEX-L-Ala-C $4-\mathrm{NO}_{3}$-L-Lac & $54.10 \pm 0.10$ & $6.78 \pm 0.01$ & $0.19 \pm 0.02$ & $0.046 \pm 0.002$ \\
\hline & IN-L-Ala-C $4-\mathrm{NO}_{3}$-L-Lac & $107.21 \pm 0.21$ & $1.80 \pm 0.07$ & $0.10 \pm 0.01$ & $1.600 \pm 0.005$ \\
\hline & TEX-L-Ala-C ${ }_{4}-\mathrm{L}-\mathrm{Lac}$ & $107.33 \pm 0.19$ & $1.28 \pm 0.04$ & $0.12 \pm 0.02$ & $1.610 \pm 0.004$ \\
\hline & TEX-L-Phe-C ${ }_{4}$-L-Lac & $108.21 \pm 0.20$ & $1.30 \pm 0.02$ & $0.13 \pm 0.02$ & $1.609 \pm 0.004$ \\
\hline & TEX-L-Ala-C $4-\mathrm{NO}_{3}$-L-Lac & $108.08 \pm 0.11$ & $1.27 \pm 0.02$ & $0.09 \pm 0.01$ & $1.590 \pm 0.003$ \\
\hline \multirow[t]{2}{*}{3} & IN-L-Ala-C ${ }_{4}-\mathrm{L}-\mathrm{Lac}$ & $143.00 \pm 0.18$ & $1.000 \pm 0.005$ & $0.011 \pm 0.003$ & $2.020 \pm 0.005$ \\
\hline & IN-L-Phe-C 4 -L-Lac & $143.02 \pm 0.15$ & $1.020 \pm 0.007$ & $0.010 \pm 0.002$ & $1.920 \pm 0.005$ \\
\hline \multirow[t]{6}{*}{4} & IN-L-Ala-C ${ }_{4}-\mathrm{L}-\mathrm{Lac}$ & $11.72 \pm 0.17$ & $3.90 \pm 0.03$ & $0.12 \pm 0.02$ & $0.028 \pm 0.005$ \\
\hline & IN-L-Phe-C ${ }_{4}$-L-Lac & $11.22 \pm 0.15$ & $4.10 \pm 0.03$ & $0.11 \pm 0.02$ & $0.023 \pm 0.005$ \\
\hline & IN-L-Ala-C $4-\mathrm{NO}_{3}$-L-Lac & $11.36 \pm 0.17$ & $4.66 \pm 0.07$ & $0.15 \pm 0.01$ & $0.030 \pm 0.002$ \\
\hline & TEX-L-Ala-C ${ }_{4}-\mathrm{L}-\mathrm{Lac}$ & $11.98 \pm 0.12$ & $4.25 \pm 0.02$ & $0.12 \pm 0.01$ & $0.024 \pm 0.002$ \\
\hline & TEX-L-Phe-C ${ }_{4}$-L-Lac & $11.24 \pm 0.12$ & $4.52 \pm 0.05$ & $0.17 \pm 0.03$ & $0.029 \pm 0.007$ \\
\hline & TEX-L-Ala-C ${ }_{4}-\mathrm{NO}_{3}$-L-Lac & $12.08 \pm 0.11$ & $4.88 \pm 0.03$ & $0.11 \pm 0.01$ & $0.023 \pm 0.001$ \\
\hline \multirow[t]{6}{*}{5} & IN-L-Ala-C - $^{-L}-\mathrm{Lac}$ & $106.21 \pm 0.20$ & $1.38 \pm 0.02$ & $0.05 \pm 0.01$ & $0.330 \pm 0.012$ \\
\hline & IN-L-Phe-C ${ }_{4}$-L-Lac & $104.96 \pm 0.18$ & $1.37 \pm 0.02$ & $0.05 \pm 0.02$ & $0.390 \pm 0.012$ \\
\hline & IN-L-Ala-C ${ }_{4}-\mathrm{NO}_{3}$-L-Lac & $106.00 \pm 0.18$ & $1.37 \pm 0.03$ & $0.06 \pm 0.01$ & $0.330 \pm 0.015$ \\
\hline & TEX-L-Ala-C ${ }_{4}-\mathrm{L}-\mathrm{Lac}$ & $105.92 \pm 0.22$ & $1.27 \pm 0.05$ & $0.06 \pm 0.01$ & $0.360 \pm 0.013$ \\
\hline & TEX-L-Phe-C ${ }_{4}$-L-Lac & $105.33 \pm 0.15$ & $1.39 \pm 0.01$ & $0.07 \pm 0.02$ & $0.330 \pm 0.017$ \\
\hline & TEX-L-Ala-C ${ }_{4}-\mathrm{NO}_{3}$-L-Lac & $106.02 \pm 0.11$ & $1.39 \pm 0.03$ & $0.05 \pm 0.01$ & $0.308 \pm 0.011$ \\
\hline & IN-L-Ala-C ${ }_{4}-\mathrm{NO}_{3}-\mathrm{L}-\mathrm{Lac}$ & $161.40 \pm 0.15$ & $1.34 \pm 0.03$ & $0.08 \pm 0.01$ & $1.390 \pm 0.009$ \\
\hline & TEX-L-Ala-C ${ }_{4}-\mathrm{L}-\mathrm{Lac}$ & $162.50 \pm 0.17$ & $1.21 \pm 0.05$ & $0.08 \pm 0.01$ & $1.430 \pm 0.007$ \\
\hline & TEX-L-Phe-C ${ }_{4}$-L-Lac & $164.06 \pm 0.11$ & $1.30 \pm 0.02$ & $0.09 \pm 0.02$ & $1.360 \pm 0.007$ \\
\hline & TEX-L-Ala-C ${ }_{4}-\mathrm{NO}_{3}$-L-Lac & $164.03 \pm 0.12$ & $1.30 \pm 0.02$ & $0.10 \pm 0.01$ & $1.359 \pm 0.005$ \\
\hline \multirow[t]{6}{*}{8} & IN-L-Ala-C ${ }_{4}$-L-Lac & $55.48 \pm 0.11$ & $0.776 \pm 0.009$ & $0.017 \pm 0.002$ & $7.200 \pm 0.009$ \\
\hline & IN-L-Phe-C ${ }_{4}-\mathrm{L}-\mathrm{Lac}$ & $55.59 \pm 0.12$ & $0.771 \pm 0.012$ & $0.015 \pm 0.002$ & $7.150 \pm 0.009$ \\
\hline & IN-L-Ala-C ${ }_{4}-\mathrm{NO}_{3}$-L-Lac & $55.62 \pm 0.12$ & $0.771 \pm 0.011$ & $0.014 \pm 0.003$ & $7.610 \pm 0.011$ \\
\hline & TEX-L-Ala-C 4 -L-Lac & $55.27 \pm 0.13$ & $0.729 \pm 0.009$ & $0.017 \pm 0.003$ & $7.470 \pm 0.012$ \\
\hline & TEX-L-Phe-C ${ }_{4}$-L-Lac & $55.53 \pm 0.11$ & $0.731 \pm 0.011$ & $0.015 \pm 0.002$ & $7.000 \pm 0.009$ \\
\hline & TEX-L-Ala-C $4-\mathrm{NO}_{3}$-L-Lac & $54.09 \pm 0.11$ & $0.729 \pm 0.013$ & $0.010 \pm 0.002$ & $7.240 \pm 0.009$ \\
\hline \multirow[t]{6}{*}{9} & IN-L-Ala-C ${ }_{4}$-L-Lac & $59.93 \pm 0.11$ & $1.12 \pm 0.03$ & $0.011 \pm 0.003$ & $2.149 \pm 0.011$ \\
\hline & IN-L-Phe-C ${ }_{4}$-L-Lac & $59.98 \pm 0.11$ & $1.15 \pm 0.02$ & $0.012 \pm 0.003$ & $2.180 \pm 0.012$ \\
\hline & IN-L-Ala-C ${ }_{4}-\mathrm{NO}_{3}$-L-Lac & $60.60 \pm 0.12$ & $1.11 \pm 0.01$ & $0.011 \pm 0.023$ & $2.200 \pm 0.012$ \\
\hline & TEX-L-Ala-C ${ }_{4}$-L-Lac & $60.67 \pm 0.13$ & $1.13 \pm 0.01$ & $0.010 \pm 0.003$ & $2.198 \pm 0.015$ \\
\hline & TEX-L-Phe-C ${ }_{4}$-L-Lac & $60.22 \pm 0.10$ & $1.16 \pm 0.02$ & $0.010 \pm 0.001$ & $2.230 \pm 0.013$ \\
\hline & TEX-L-Ala- $\mathrm{C}_{4}-\mathrm{NO}_{3}$-L-Lac & $60.63 \pm 0.08$ & $1.17 \pm 0.01$ & $0.009 \pm 0.001$ & $2.159 \pm 0.013$ \\
\hline
\end{tabular}


Table 3 Recovery tests of $f-L-T_{4}, f-D-T_{4}, f-L-T_{3}$ and TSH in whole blood samples

\begin{tabular}{|c|c|c|c|c|}
\hline Microsensor based on & $\mathrm{f}-\mathrm{L}-\mathrm{T}_{3} \%$, recovery & $\mathrm{f}-\mathrm{L}-\mathrm{T}_{4} \%$, recovery & $\mathrm{f}-\mathrm{D}-\mathrm{T}_{4} \%$, recovery & TSH $\%$, recovery \\
\hline IN-L-Ala-C ${ }_{4}$-L-Lac & $98.92 \pm 0.09$ & $98.70 \pm 0.05$ & $99.22 \pm 0.04$ & $99.21 \pm 0.02$ \\
\hline IN-L-Phe-C ${ }_{4}$-L-Lac & $98.72 \pm 0.09$ & $98.99 \pm 0.05$ & $99.05 \pm 0.04$ & $99.20 \pm 0.02$ \\
\hline TEX-L-Ala-C ${ }_{4}$-L-Lac & $98.50 \pm 0.07$ & $98.20 \pm 0.07$ & $98.32 \pm 0.05$ & $99.32 \pm 0.02$ \\
\hline TEX-L-Phe-C ${ }_{4}$-L-Lac & $99.01 \pm 0.07$ & $99.03 \pm 0.07$ & $99.99 \pm 0.02$ & $99.99 \pm 0.02$ \\
\hline TEX-L-Ala-C $4-\mathrm{NO}_{3}-\mathrm{L}-\mathrm{Lac}$ & $99.24 \pm 0.08$ & $99.56 \pm 0.04$ & $99.93 \pm 0.04$ & $99.98 \pm 0.02$ \\
\hline
\end{tabular}

\section{Analytical applications}

The response characteristics, selectivity, and reliability of the microsensors made possible the simultaneous assay of $\mathrm{f}-\mathrm{L}-\mathrm{T}_{3}, \mathrm{f}-$ $\mathrm{L}-\mathrm{T}_{4}, \mathrm{f}-\mathrm{D}-\mathrm{T}_{4}$, and TSH in whole blood samples. The whole blood samples were analysed as collected from the nine patients, immediately after they were collected from patients. Diagrams were recorded (Fig. 1), and signatures ( $t_{\text {off }}$ values) identified for $\mathrm{f}-\mathrm{L}-\mathrm{T}_{3}, \mathrm{f}-\mathrm{L}-\mathrm{T}_{4}, \mathrm{f}-\mathrm{D}-\mathrm{T}_{4}$ and TSH in each diagram. After identifying the signature for each biomarker (f-L- $\mathrm{T}_{3}, \mathrm{f}-\mathrm{L}-\mathrm{T}_{4}, \mathrm{f}-\mathrm{D}-\mathrm{T}_{4}$ and TSH), the corresponding $t_{\mathrm{on}}$ value was read (see Fig. 1) and introduced in the equation of calibration of each sensors, to obtain the value of the concentration.

Results presented in Table 2 shown a good correlations between the results obtained for the assay of f-L-T $\mathrm{T}_{3}, \mathrm{f}-\mathrm{L}-\mathrm{T}_{4}$, f-D- $\mathrm{T}_{4}$, and TSH in whole blood samples. Recovery tests were performed by comparing the amounts of f-L-T $\mathrm{T}_{3}, \mathrm{f}-\mathrm{L}-\mathrm{T}_{4}, \mathrm{f}-\mathrm{D}-\mathrm{T}_{4}$, and TSH determined in whole blood samples using ELISA (the standard method), and the proposed microsensors. The values of recoveries (Table 3) shown for each sensor, and each compound a very good correlation, given by the amount of compound found using the proposed microsensors reported to the amount of the same compound found in the sample blood sample using ELISA, the recovery being expressed as \% recovery. All relative standard deviations recorded were less than $1.00 \%$, proving a high precission and reliability of the measurements.

\section{Conclusion}

Six stochastic microsensors based on diamond paste modified with inulins and ionic liquids were proposed for the assay of f-L$\mathrm{T}_{4}$, f-D- $\mathrm{T}_{4}, \mathrm{f}-\mathrm{L}-\mathrm{T}_{3}$ and TSH in whole blood samples. The microsensors were selective, and enantioselective and presented high sensitivity and reliability for the assay of thyroid hormones in whole blood samples. Regarding all response characteristics as well as the signatures of the hormones, the sensor of choice for simultaneous assay of thyroid hormones is the one based on TEX-L-Ala- $\mathrm{C}_{4}-\mathrm{NO}_{3}$-L-Lac.

Compared with ELISA and chemiluminescence methods used in clinical laboratories for their determination, the main advantages of the proposed method are: there is no need for sample pretreatment before assay, samples being used as taken from the patient, all four hormones can be determined in one run, low cost, decreased time of determination, high sensitivities and lower limits of determination.

\section{Conflicts of interest}

There are no conflicts to declare.

\section{Acknowledgements}

This work was supported by UEFISCDI PNIII Program PCE Contract nr. 46/2017.

\section{References}

1 G. S. Ginsburg and H. F. Willard, Genomic and personalized medicine: foundations and applications, Transl. Res., 2009, 154, 277-287.

2 J. Schmidt, Stochastic sensors, J. Mater. Chem., 2005, 15, 831840.

3 R. I. Stefan-van Staden, G. Mitrofan, I. R. Comnea-Stancu, J. K. van Staden, C. Kapnissi-Christodoulou and $\mathrm{H}$. Y. Aboul-Enein, Ionic liquids for the molecular enantiorecognition of free $\mathrm{L}_{3} \mathrm{~T}_{3}, \mathrm{~L}-\mathrm{T}_{4}$ and $\mathrm{D}-\mathrm{T}_{4}, R S C A d v$., 2015, 5, 75451-75457.

4 G. Mitrofan, R. I. Stefan-van Staden, I. R. Comnea-Stancu, J. K. van Staden, G. Bazylak, C. Christodoulou and H. Y. Aboul-Enein, Fast screening of whole blood samples and pharmaceutical compounds for Enantiorecognition of free L-T $\mathrm{T}_{3}, \mathrm{~L}^{-} \mathrm{T}_{4}$ and D-T $\mathrm{T}_{4}$, Chirality, 2015, 27, 973-978.

5 L. E. Braveman and D. S. Cooper, The Thyroid: A Fundamental and Clinical Text, Lippincott Williams and Wilkins, Philadelphia, US, 2013.

6 M. R. Haymart, S. L. Glinberg, J. Liu, R. S. Sippel, J. C. Jaume and $\mathrm{H}$. Chen, Higher serum TSH in thyroid cancer patients occurs independent of age and correlates with extrathyroidal extension, Clin. Endocrinol., 2009, 71, 434439.

7 J. E. Midgley, Direct and indirect free thyroxine assay methods: theory and practice, Clin. Chem., 2001, 47, 13531363.

8 Clinical and Laboratory Standards Institute (CLSI), Measurement of free thyroid hormones; approved guideline, CLSI, Wayne, PA, ISBN 1-56238-548-8, 2004.

9 O. P. Soldin and S. J. Soldin, Thyroid hormone testing by tandem mass spectrometry, Clin. Biochem., 2011, 44, 89-94.

10 D. Wang and H. M. Srapleton, Analysis of thyroid hormones in serum by liquid chromatography-tandem mass spectrometry, Anal. Bioanal. Chem., 2011, 397, 1831-1839. 
11 V. Samanidou, H. Gika and I. N. Papadoyannis, Rapid HPLC analysis of thyroid gland hormones tri-iodothyronine (T-3) and thyroxine (T-4) in human biological fluids after SPE, $J$. Liq. Chromatogr. Relat. Technol., 2000, 23, 681-692.

12 S. Georgiou and I. Christofidis, Radioimmunoassay of free thyroxine $\left(\mathrm{T}_{4}\right)$ using ${ }^{125} \mathrm{I}$-labeled $\mathrm{T}_{4}$-IgG complex with very large molecular weight, Clin. Chim. Acta, 1996, 244, 209-220.

13 X. Wang, H. Chen, J.-M. Lin and X. Ying, Development of a highly sensitive and selective microplate chemiluminescence enzyme immunoassay for the determination of free thyroxine in human serum, Int. J. Biol. Sci., 2007, 3, 274-280.

14 M. S. Cabayo, M. Mauri, R. Alfayate and F. Soria, Analytical and clinical evaluation of TSH and thyroid hormones by electrochemiluminescent immunoassays, Clin. Biochem., 1999, 32, 395-403.

15 A. Abdulaziz and A. A. El-Reweny, The diagnostic utility of third generation TSH electro-chemiluminescence immunoassay in detecting the incidence of thyroid dysfunctions in Saudi Arabia, Med. J. Cairo Univ., 2011, 79, 497-507.

16 F. Kazerouni and H. Amirrasouli, Performance characteristics of three automated immunoassays for thyroid hormones, Caspian J. Intern. Med., 2012, 3, 400-404.

17 L. Shi, Z. Shi, J. Zhang, Q. Ma, D. Kong, L. Yang and Y. Tan, The measurement and application of TSH-IRMA levels among different age groups in areas with iodine deficiency disorders, Chin. Med. Sci. J., 1995, 10, 30-33.

18 L. Grasso, L. Bartalena, C. Mammoli, E. Martino, A. C. Kessler and A. Pinchera, Serum TSH measurements by a sensitive enzyme immunoassay discriminate euthyroid from hyperthyroid subjects and avoid the need for TRH test during suppressive therapy with L-thyroxine, Clin. Biochem., 1987, 20, 197-200.

19 C. Seidel, D. Ziegelitz, A. Weber, T. Dittmer, H. Gerl, G. Knappe and H. J. Correns, Clinical value of a sensitive TSH-RIA, Endokrinologie, 1982, 80, 181-193.

20 A. Das and M. V. Sangaranarayanan, Electroanalytical sensor based on unmodified screen-printed carbon electrode for the determination of levo-thyroxine, Electroanalysis, 2014, 27, 360-367.

21 R. I. Stefan, J. F. van Staden and H. Y. Aboul-Enein, Determination of $(+)-3,3^{\prime}, 5$-triiodo-L-thyronine $\left(\mathrm{L}-\mathrm{T}_{3}\right)$ from serum using a sequential injection analysis/immunosensor system, J. Immunoassay Immunochem., 2003, 25, 348-355.

22 R. I. Stefan, J. F. van Staden, H. Y. Aboul-Enein, M. C. Mirica, I. Balcu and N. Mirica, Determination of $(+)-3,3^{\prime}, 5,5^{\prime}-$ tetraiodo-L-thyronine $\left(\mathrm{L}-\mathrm{T}_{4}\right)$ in serum and pharmaceutical formulations using a sequential injection analysis/ immunosensor system, J. Immunoassay Immunochem., 2008, 29, 348-355.

23 H. Wang, X. Wu, P. Dong, C. Wang, J. Wang, Y. Liu and J. Chen, Electrochemical biosensor based on interdigitated electrodes for determination of thyroid stimulating hormone, Int. J. Electrochem. Sci., 2014, 9, 12-21.

24 R. I. Stefan and H. Y. Aboul-Enein, The construction and characterization of an amperometric immunosensor for the thyroid hormone (+)-3,3',5,5'-tetraiodo-L-thyronine (LT4), J. Immunoassay Immunochem., 2002, 23, 429-437.

25 B. Zhang, D. Tang, B. Liu, Y. Cui, H. Chen and G. Chen, Nanogold-functionalized magnetic beads with redox activity for sensitive electrochemical immunoassay of thyroid-stimulating hormone, Anal. Chim. Acta, 2012, 711, 17-23.

26 H. Wang, P. Dong, D. Di and X. Wu, Interdigitated microelectrodes biosensor with nanodot arrays for thyroid stimulating hormone detection, Micro Nano Lett., 2013, 8, 11-14.

27 S. Kubitschko, J. Spinke, T. Bruckner, S. Pohl and N. Oranth, Festivity Enhancement of optical immunosensors with nanoparticles, Anal. Biochem., 1997, 253, 112-122.

28 M. Gao, F. Yu, L. Changjun, J. Choo and L. Chen, Fluorescent chemical probes for accurate tumor diagnosis and targeting therapy, Chem. Soc. Rev., 2017, 46, 2237-2271.

29 X. Han, X. Song, F. Yu and L. Chen, A ratiometric nearinfrared fluorescent probe for quantification and evaluation of selenocysteine-protective effects in acute inflammation, Adv. Funct. Mater., 2017, 27, 1700769.

30 X. Han, X. Song, F. Yu and L. Chen, A ratiometric fluorescent probe for imaging and quantifying anti-apoptotic effects of GSH under temperature stress, Chem. Sci., DOI: 10.1039/ C7SC02888A.

31 L. R. Mandoc, I. Moldoveanu, R. I. Stefan-van Staden and E. M. Ungureanu, Pattern recognition of $\mathrm{Cu}(\mathrm{II}), \mathrm{Pb}(\mathrm{II})$, $\mathrm{Hg}(\mathrm{II})$, and $\mathrm{Cd}(\mathrm{II})$ in waste waters, Microsys. Technol., 2017, 23, 1141-1145.

32 R. I. Stefan-van Staden, I. R. Comnea-Stancu and C. C. SurduBob, Molecular screening of blood samples for the simultaneous detection of CEA, HER-1, NSE, CYFRA 21-1 using stochastic sensors, J. Electrochem. Soc., 2017, 164, B267-B273.

33 L. A. Gugoasa, R. I. Stefan-van Staden, A. J. M. Al-Ogaidi and C. Stanciu-Gavan, Molecular recognition of colon cancer biomarkers: P53, KRAS and CEA in whole blood samples, $J$. Electrochem. Soc., 2017, 164, B443-B447. 